\title{
Monte Carlo Simulation in Valuation of INVESTMENT PRojects
}

\author{
Branislav Maric \& Vanja Grozdic \\ University of Novi Sad, Faculty of Technical Sciences, Trg Dositeja Obradovića 6, 21000 Novi Sad
}
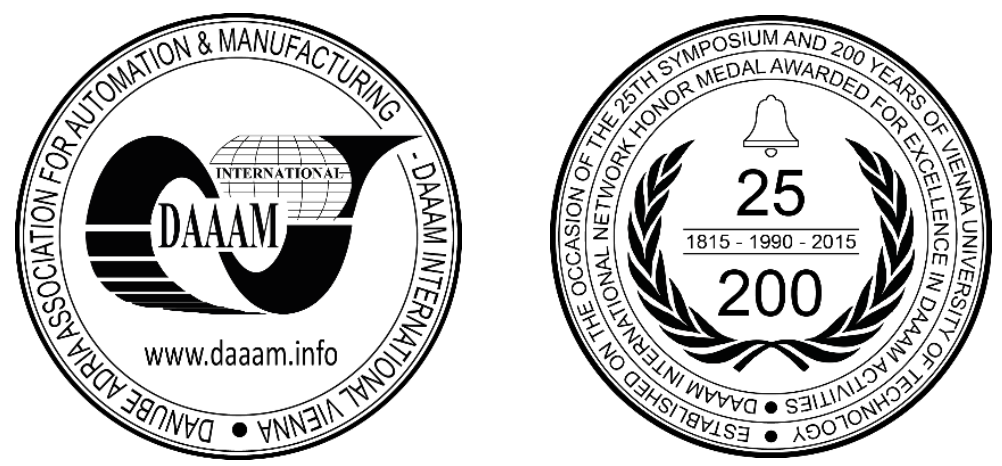

This Publication has to be referred as: Maric, B[ranislav] \& Grozdic, V[anja] (2016). Monte Carlo Simulation in Valuation of Investment Projects, Proceedings of the 27th DAAAM International Symposium, pp.0686-0692, B. Katalinic (Ed.), Published by DAAAM International, ISBN 978-3-902734-08-2, ISSN 1726-9679, Vienna, Austria

DOI: 10.2507/27th.daaam.proceedings.099

\begin{abstract}
Valuation of investment projects is a crucial part of the investment decision making process. The most important part of any investment analysis are discounted cash flow methods: net present value (NPV) and internal rate of return (IRR). The aim of this paper is application of risk analysis technique - Monte Carlo simulation, including sensitivity and scenario analysis, in investment project valuation. For this purpose, we have used an investment project - the new plant for the combined production of electrical and thermal energy, as a case study. The input (key) variables used in this analysis, for performing a Monte Carlo simulation, are total revenue, variable costs, initial investment and discount rate, determined by the sensitivity analysis. As the output variables we have used net present value (NPV) and internal rate of return (IRR). Monte Carlo simulation results show that the probability of the project's success is $86.1 \%$, according to the NPV rule, and $91.9 \%$, according to the IRR rule of project's acceptance.
\end{abstract}

Keywords: investment project; sensitivity analysis; scenario analysis; Monte Carlo simulation

\section{Introduction}

This paper discusses the use of risk analysis techniques in investment decisions. Making a decision on the basis of assumptions, expectations, estimates and forecasts of future events involves taking risks. Risk and uncertainty characterize situations where the actual outcome for a particular event or activity is likely to deviate from the estimate or forecast value [1]. Risk can be quantified as folows:

$$
\text { Risk = Event's probability x Magnitude of loss/gain }
$$

Generaly, sensitivity analysis is about identification of critical factors and how their change affects behavior of investment project. Scenario analysis is a simple risk analysis technique which determines the „base case scenario“, „,best case scenario“ and „worst case scenario“ for the project. Monte Carlo simulation is a method in which we assighn probability distributions to the input variables (critical factors) and, on that basis, we calculate output variables and the probability of their occurence. According to PMI [2], Monte Carlo simulation is a technique that computes or iterates the 
project cost or schedule many times using input values selected at random from probability distributions of possible costs or durations, to calculate a distribution of possible total project cost or completion dates.

For the purpose of this paper we have used an investment project form the energy industry, as a case study. The most commonly used discounted cash flow methods are net present value (NPV) and internal rate of return (IRR), which were used as output variables in this analysis.

\section{Brief literature review}

Many researches have examined the use of risk analysis techniques in investment decision making process. Jovanovic [3] examines the aplicaton of sensitivity analysis, effect of discount rate and total investment value on the NPV, in investment project evaluation and concludes that, using this technique, we are able to obtain a great deal of information about the effect of input parameters on the examined criteria for investment project decision making. Acording to J.K. Kaldellis et al. [4], a remarkable growth of the energy production sector is expected based on the anaylsis of the influance of techno - economic parameters - such as capital cost, retutn on investment, electricity price etc. - on the economic viability and attractiveness of investment. E. Borgonovo et al. [5] applied sensitivity analysis to the project finance case study and analyzed investment criteria related to both the investors's and lenders' perspectives, where results showed that revenue assumptions and construction costs, are the most important drivers of economic performance from the perspectives of both sponsors and lenders. Monte Carlo simulation (MCS) is a widely used technique in the risk analysis of the energy projects. F. Kienzle [6] applies Monte Carlo simulation in a valuation of investments in multi - energy conversion, where he uses energy prices (gas, electricity and heat) as the input variables and calculate the present values (PVs) of an energy hub, and their distribution. L. Zhu [7] employs MCS in a nuclear power investment valuation where several technical and economic risk factors (investment cost, generating cost, electricity prices and nuclear accident) have been taken into account in the model. J. Munoz et al. [8] calculate NPV of an investment in a wind energy plant using MCS and input variables such as wind and production parameters, electricity price and investment cost, and compare this approach with the traditional NPV method. H. Laurikka [9] presents a simulation model which is used to explore the impact of the input variables, such as market prices of electricity, emission allowance and fuels on the investment's NPV, using two case studies: modifications of an existing condensing power plant and a new combined heat and power plant. F.A. Roques [10] illustrate, through a simple net present value model of three base load technologies (coal, gas, and nuclear plants), how Monte Carlo simulation can capture the impact of a wide range of uncertainties and risks, such as energy prices, fixed and variable costs, discount rate etc.

\section{Investment project valuation - case study}

Remer and Nieto [11] categorize methods and techniques used to evaluate economic desirability of projects into five basic types: net present value methods, rate of return methods, ratio methods, payback methods and accounting methods. A central feature of any investment analysis is discounted cash flow (DCF), which takes into consideration the time value of money, is regarded as theoretically correct, and includes at least four different discounting models: net present value (NPV), internal rate of return (IRR), modified internal rate of return (MIRR), and profitability index (PI) [12]. For the purpose of this study we will briefly explain the two most important discounted cash flow methods, i.e the net present value (NPV) and intetnal rate of return (IRR) method.

Net present value (NPV) is calculated by subtracting the initial investment from the sum of discounted values of future cash flows of the project. The NPV rule: If the NPV is positive - accept the project. The NPV formula:

$$
N P V=\sum_{t=1}^{n} \frac{C F_{t}}{(1+r)^{t}}-C F_{0}
$$

Internal rate of return (IRR) is a discount rate that makes NPV equals zero. The IRR rule: If the IRR is greater than the cost of capital (discount rate) - accept the project. The IRR can be calculated using this formula:

$$
\sum_{t=1}^{n} \frac{C F_{t}}{(1+r)^{t}}-C F_{0}=0
$$

For the purpose of this analysis, as a case study, we have used an investment project - the new plant for the combined production of electrical and thermal energy. The main objective of the project is the production of additional electrical and thermal energy. Duration time of the project is 20 years, and estimated construction time is 4 years. The calculation of the sales revenues from the electrical and thermal energy is based on the production of electrical and thermal energy in $\mathrm{kWh}$ and their selling prices. These revenues presents cash inflows of the project. Cash outflows of the project include initial investment, operational costs and income tax. Operational costs are divided into fixed costs (maintenance, earnings, insurance...) and variable costs (natural gas procurement costs and tax on emissions of NOx). Variable costs, i.e. natural 
gas procurement costs, have the dominant position in total costs structure ( $80 \%$ of the total costs). Future cash flows were discounted with the rate of $9 \%$. The main results of the project's cash flow analysis are:

- $\quad$ Net present value $(\mathrm{NPV})=598.5 \mathrm{mil} €$,

- Internal rate of return (IRR) $=35 \%$

- $\quad$ Payback period $=3$ years $(7$ years, including construction time of 4 years $)$

\section{Sensitivity and scenario analysis}

Economic and financial analysis is based on the values which are subject to change over time and thus may affect the profitability of the investment project. This is the main reason for conducting sensisitivity analysis which has the goal to measure the effect of changes in a key variables on investment project's output (e.g. NPV). To perform a sensitivity analysis, all variables are fixed, except for the variable under consideration, which is allowed to fluctuate. As for this project, we have variables whose values are changing very offten, but beside that, we should bear in mind the fact that, regardless of the changing energy prices over time (e.g. electricity price is stable in one period, but natural gas price in that period is changing intensively), observed in the longer term, they grow and follow each other.

While sensitivity analysis measures sensitivity of project's NPV by varying one key variable at the time, scenario analysis constructs scenarios where several key variables change in each scenario. In this case, project is evaluated by looking his NPVs in all constructed scenarios. It is always possible to create a large number of alternative scenarios, but it is convenient to limit these scenarios to specific events and economic conditions that would be of great significance to the project. As mentioned before, this technique determines the „,base case scenario“, „best case scenario“ and „worst case scenario" for the project. Table 1. and Fig. 1. show the sensitivity and scenario analysis, respectively.

\begin{tabular}{|c|c|c|c|c|c|}
\hline No & Variable & $\begin{array}{c}\text { Deviation } \\
(\boldsymbol{\%})\end{array}$ & $\begin{array}{c}\text { NPV after } \\
\text { change (in mil } € \text { ) }\end{array}$ & $\begin{array}{c}\text { Absolute change } \\
\text { (in mil } € \text { ) }\end{array}$ & $\begin{array}{c}\text { Relative } \\
\text { change }(\%)\end{array}$ \\
\hline 1. & $\begin{array}{c}\text { Revenue from electricity energy } \\
\text { sale }\end{array}$ & -10 & 358.1 & 240.4 & 40 \\
\hline 2. & $\begin{array}{c}\text { Revenue from thermal energy } \\
\text { sale }\end{array}$ & -10 & 573.2 & 25.3 & 4 \\
\hline 3. & Initial investment & +10 & 570.8 & 27.7 & 5 \\
\hline 4. & Maintaince cost & +10 & 588.9 & 9.6 & 2 \\
\hline 5. & Earnings cost & +10 & 596.3 & 2.2 & 0.4 \\
\hline 6. & Insurance premiums & +10 & 596.1 & 2.4 & 0.4 \\
\hline 7. & Obligations to the state & +10 & 597.5 & 1 & 0.2 \\
\hline 8. & Other costs & +10 & 598 & 0.5 & 0.08 \\
\hline 9. & Natural gas procurement cost & +10 & 442.9 & 155.6 & 26 \\
\hline 10. & Tax on emissions of NOx & +10 & 598.4 & 0.1 & 0.02 \\
\hline 11. & Income tax & +10 & 591.8 & 6.7 & 1 \\
\hline 12. & Discount rate & +10 & 545.5 & 53 & 9 \\
\hline
\end{tabular}

Table 1. Sensitivity analysis of the project

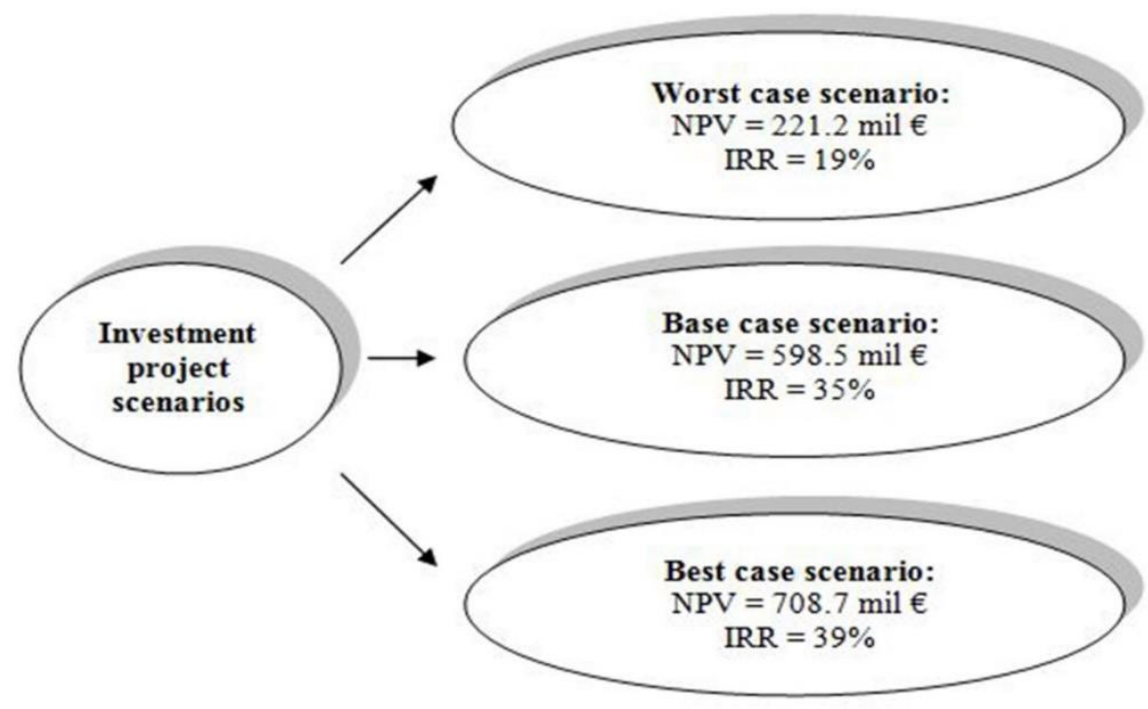

Fig. 1. Scenario analysis of the project 
The results of the project's sensitivity analysis (Table 1.) show that the most influential variables on the investment project behavior are total revenue (production volume and the selling prices of electrical and thermal energy), varible costs (natural gas procurement cost), initial investment and discount rate. Generaly, the largest risk of investing in this project is related to the energy prices. If the price of natural gas increase, the production of electrical and thermal energy will become more expensive. On the other hand, increase of the electrical energy price, as well as the thermal energy price, will positively affect the project's profitability. As mentioned before, the price of electrical and thermal energy depends on the movement of the natural gas price. According to this, we can conclude that the project is most sensitive to changes in the natural gas price, which is logical, because this fuel is $80 \%$ of total costs of the production. In the case when only natural gas price is changing and other variables remain constant, the project is profitable as long as that increase does not reach $50 \%$.

Unlike the sensitivity analysis, scenario analysis provides a likiely range of project's NPV and IRR (Fig. 1.). Base scenario assumes that the new plant will work during the whole year. In that case, the project's NPV is 598.5 mil $€$ and IRR is $35 \%$. However, engagement of this plant which uses expensive fuel such as natural gas, can drasticly decrese when the new capacity, which uses less expensive fuel, enters into operation for production of electrical energy. In this case, the plant will work only during the heating season, in cogeneration regime. This situation is considered as the worst case scenario, when both variables, total revenue and variable costs, are reduced by $40 \%$. Best case scenario assumes increase of the energy (electrical, thermal and gas) prices, i.e. total revenue and variable costs by $10 \%$. However, scenario analysis does not specify how likely are the occurrences of the scenarios.

\section{Monte Carlo simulation}

Since its conception in mid-20th century, Monte Carlo simulations have grown in popularity among the scientific community, becoming a mainstay of stochastic decision making tools, used in many fields including real options, air pollution, workspace-visualization, or hydro power plants availability, among a myriad of others [13]. The term Monte Carlo simulation refers to a broad spectrum of mathematical models and algorithms, whose most prominent feature is the use of random numbers in solving various problems [14]. The Monte Carlo method simulates the full system many times, each time randomly choosing a value for each variable from its probability distribution [15]. According to Hacura et al. [16], during the simulation process, random scenarios are built up using input values for the project's key uncertain variables, which are selected from appropriate probability distributions, and after which the results are collected and analyzed statistically so as to arrive at a probability distribution of the potential outcomes of the project, and to estimate various measures of project risk. Generaly, we need to take six steps to perform a Monte Carlo simulation:

1. Identification of the input variables

2. Identifaction of the output variables

3. Assigning probability distributions to the input variables

4. Establishing the relationship between the input variables

5. Running a simulation

6. Interpretation of the results

The first step in Monte Carlo simulation is to identify the input variables - key variables whose change has the greatest influence on the project. According to the sensitivity analysis, these variables are total revenue (the sum of electrical and thermal energy sale revenues), variable costs (natural gas procurement cost), initial investment and discount rate. The next step is to identify the output variables, which are net present value (NPV) and internal rate of return (IRR). The third step is related to defining of assumptions, i.e. assigning probability distributions to the input variables. Based on the opinions of experts and the historical data we have chosen the next probability distributions for the input variables:

- Total revenue - Triangular distribution - with the minimum, most likely and maximum values.

- Variable costs - Normal distribution - with the mean and standard deviation.

- Initial investment - Uniform distribution - with the minimum and maximum value.

- Discount rate - Triangular distribution - with the minimum, most likely and maximum values.

The next step is to define correlation between the input variables. Positive correlation coeficients, i.e. statistical dependency, between two input variables - total revenue and variable costs, are considered in the simulation. This means that when variable costs are growing, total revenues are also growing. This is related to the fact, as we mentioned before, that there is a statistical dependency between energy prices (electrical, thermal and gas) in the long term, i.e. they grow and follow each other. Between other key variables there is no statistical dependency, and they can be generated independently during the simulation. 


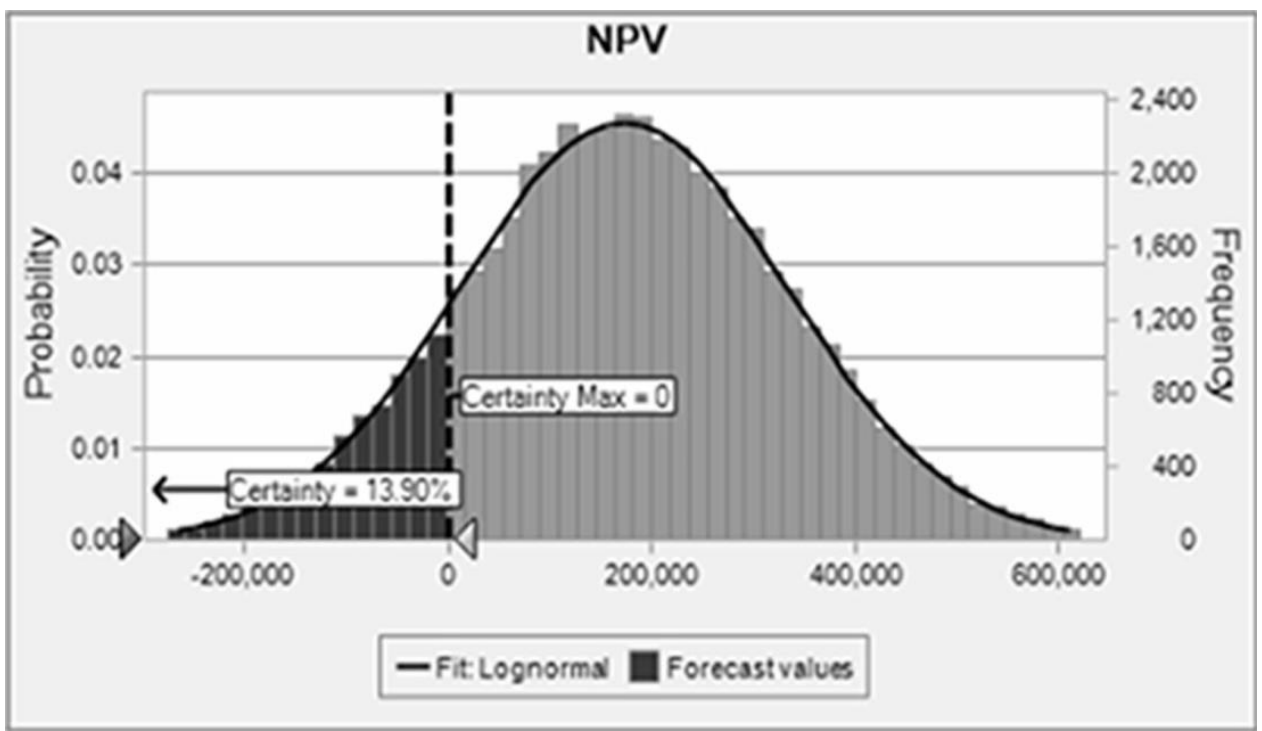

Fig. 2. Probability distribution of NPV

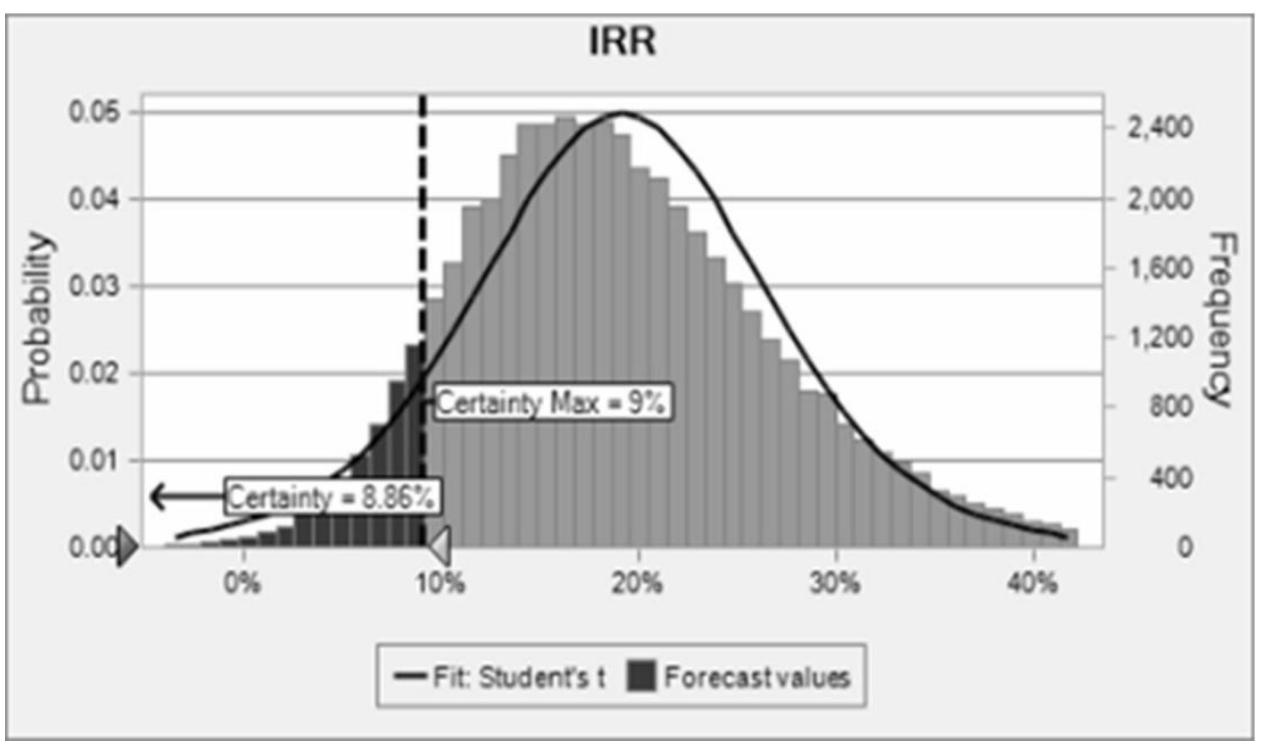

Fig. 3. Probability distribution of IRR

\begin{tabular}{|c|c|c|c|}
\hline No & Statistics & Forecast values (NPV) & Forecast values (IRR) \\
\hline 1. & Trials & 50,000 & 50,000 \\
\hline 2. & Mean & 172.9 & $19 \%$ \\
\hline 3. & Median & 172.3 & $18 \%$ \\
\hline 4. & Mode & --- & --- \\
\hline 5. & Standard Deviation & 160.2 & $8 \%$ \\
\hline 6. & Variance & $25,669,832$ & $1 \%$ \\
\hline 7. & Skewness & 0.0089 & 0.6492 \\
\hline 8. & Kurtosis & 3.01 & 4.09 \\
\hline 9. & Coeff. of Variability & 0.9266 & 0.4337 \\
\hline 10. & Minimum & -484 & $-56 \%$ \\
\hline 11. & Maximum & 832.4 & $75 \%$ \\
\hline 12. & Range Width & $1,316.4$ & $131 \%$ \\
\hline 13. & Mean Std. Error & 716.52 & $0 \%$ \\
\hline
\end{tabular}

Table 2. Statistical characteristics of the output variables 
Monte Carlo simulation was performed with 50,000 trials and the confidence level of 95\%, for the base case scenario of the investment project, using Crystal Ball risk analysis software application. The final step is related to the interpretation of the simulation results.

Fig. 2. presents the probability distribution of the NPV variable. The NPV variable has lognormal distribution, with the mean value of 172.9 mil $€$ and the standard deviation of 160.2 mil $€$ (Table 2.). The mean (172.9 mil $€$ ), actualy, represents the expected net present value (eNPV), which modifies standard NPV by multiplying each possible NPV with the probability of their occurrence. Because the difference between the mean (eNPV) and the standard deviation is not large, we can conclude that there is no high uncertainty of the project. In cases when the difference between eNPV and the standard deviation is drastic, uncertainty of the project grows, which means that the probability of loss is also high as a consequence of the high uncertainty [17]. Since the eNPV (172.9 mil €) is smaller than the base NPV (598.5 mil €), but still high and positive, we can expect that, in the reality, the project will bring lower profit than originaly calculated in the terms of determinism. We can also see (Fig. 2.) that there is $13.9 \%$ chance of negative NPV value, which means that the probability of the project's success is $86.1 \%$. Table 2. also shows, among other statistical characteristics, coefficient of variabilty of 0.9266 for the NPV variable, which is the ratio between the standard deviation and the mean (eNPV). This coefficient is below 1 , which means that the probability of loss is small.

Fig. 3. presents the probability distribution of the IRR variable. The IRR variable has student's $t$ distribution, with the mean value of $19 \%$ and the standard deviation of $8 \%$ (Table 2.). Coefficient of variability for the IRR variable is 0.4337 , also less than 1. As well for the NPV, we can see (Fig. 3.) that there is $8.9 \%$ chance for the IRR to be lower than discount rate, which is $9 \%$ in this case. This means that the probability of the project's success is $91.1 \%$, according to the IRR rule of project's acceptance.

\section{Conclusion}

Planning of investment projects is always related to the future processes, which are never absolutely known, thus the fututre events can't be predicted with full certainty. This implies that the projections carry within themselves the risk and uncertainty, which must be incorporated into the project. So, we can't predict the future, but we can reduce the risk and uncertainty related to the future processes. This can be achieved by using certain tools, such as Monte Carlo simulation, which mathematically compute future scenarios and tell us how likely are the occurrences of the possible outcomes, their probability distributions and risks related to them. Actualy, we can decide which risk to take and which to avoid, in order to make the best investment decision.

In this paper, for performing Monte Carlo simulation, we have used an investment project from the energy sector, as a case study. As the input variables we have used total revenue, variable costs, initial investment and discount rate. The output variables were net present value (NPV) and internal rate of return (IRR). The results have shown that the probability of the project's success is $86.1 \%$, according to the NPV rule, and 91.9\%, according to the IRR rule of project's acceptance.

Small number of the project's risk factors can be considered as the limitation of this study. Future research will include several investment projects from different industries, and also, detailed analysis of larger number of input and output variables, i.e. risk factors related to those projects.

\section{References}

[1] J. Raftery, Risk Analysis in Project Management, E \& FN Spon, London SE1 8HN, UK, 1994.

[2] PMBOK Guide, A guide to the project management body of knowledge: PMBOK guide, 3rd edition, Pennsylvania, USA, Project Management Institute, 2004.

[3] P. Jovanovic, Application of sensitivity analysis in investment project evaluation under uncertainty and risk, International Journal of Project Management, Vol. 17, No. 4, 1999, pp. 217-222.

[4] J.K. Kaldellis, Th.J. Gavras, The economic viability of commercial wind plants in Greece A complete sensitivity analysis, Energy Policy, Vol. 28, No. 8, 2000, pp. 509-517.

[5] E. Borgonovo, S. Gatti, and L. Peccati, What Drives Value Creation in Investment Projects? An Application of Sensitivity Analysis to Project Finance Transactions, European Journal of Operational Research, Vol. 205, No. 1, 2010, pp. 227-236.

[6] F. Kienzle, P. Ahcin, and G. Andersson, Valuing investments in multi-energy conversion, storage, and demand-side management systems under uncertainty, IEEE Transactions on Sustainable Energy, Vol. 2, No. 2, 2011, pp. 194202.

[7] L. Zhu, A simulation based real options approach for the investment evaluation of nuclear power, Computers \& Industrial Engineering, Vol. 6, No. 3, 2012, pp. 585-593.

[8] J. Munoz, J. Contreras, J. Caamano and P. Correia, Risk assessment of wind power generation project investments based on real options, Proceedings of IEEE PowerTech, 2009, pp. 1-8, Bucharest. 
[9] H. Laurikka, Option value of gasification technology within an emissions trading scheme, Energy Policy, Vol. 34, No. 18, 2006, pp. 3916-3928.

[10] F.A. Roques, D.M. Newbery, W.J. Nuttall, Fuel mix diversification incentives in liberalized electricity markets: A Mean-Variance Portfolio theory approach, Energy Economics, Vol. 30, No. 4, 2008, pp. 1831-1849.

[11] D.S. Remer and A.P. Nieto, A compendium and comparison of 25 project evaluation techniques. Part 1: Net present value and rate of return methods, International Journal of Production Economics, Vol. 42, No. 1, 1995, pp. 79-96.

[12] K. Bennouna, G. Meredith and T. Marchant, Improved capital budgeting decision making: evidence from Canada, Management Decision, Vol. 48, No. 2, 2010, pp. 225-247.

[13] R. Špicar, M. Januška, Use of Monte Carlo modified Markov Chains in capacity planning, Procedia Engineering, Vol. 100, 2015, pp. 953-959.

[14] Lj.D. Milanovic, D.D. Milanovic, and M. Misita, The Evaluation of Risky Investment Projects, in FME Transactions 2, Faculty of Mechanical Engineering, Univ. Press, Belgrade, 2010, pp. 103-106.

[15] Y.H. Kwak, L. Ingall, Exploring Monte Carlo simulation applications for project management, Risk Management, Vol. 9, No. 1, 2007, pp. 44-57.

[16] A. Hacura, M. Jadamus-Hacura, A. Kocot, Risk analysis in investment appraisal based on the Monte Carlo simulation technique", The European Physical Journal B - Condensed Matter and Complex Systems, Vol. 20 , No. 4, 2001, pp. 551-553.

[17] B. Marić, Managing Investments, Faculty of Technical Sciences, University of Novi Sad, Serbia, 2008. 